Article

\title{
Effect of Walking on Sand with Dietary Intervention in OverweightType 2 DiabetesMellitusPatients: A Randomized Controlled Trial
}

\author{
Mohamed Seyam ${ }^{1}$, Faizan Kashoo ${ }^{1, *}$, Mazen Alqahtani ${ }^{1}$, Msaad Alzhrani ${ }^{1}$, Fahad Aldhafiri ${ }^{2}$ \\ and Mehrunnisha Ahmad ${ }^{3}$ \\ 1 Department of Physical Therapy \& Health Rehabilitation, College of Applied Medical Sciences, \\ Majmaah University, Al Majmaah 11952, Saudi Arabia; m.seyam@mu.edu.sa (M.S.); \\ mm.alqahtani@mu.edu.sa (M.A.); m.alzhrani@mu.edu.sa (M.A.) \\ 2 Public Health Department, College of Applied Medical Sciences, Majmaah University, \\ Al Majmaah 11952, Saudi Arabia; f.aldhafiri@mu.edu.sa \\ 3 Department of Nursing, College of Applied Medical Sciences, Majmaah University, \\ Al Majmaah 11952, Saudi Arabia; m.ahmer@mu.edu.sa \\ * Correspondence: f.kashoo@mu.edu.sa; Tel.: +966-53-814-9226
}

Received: 11 August 2020; Accepted: 22 September 2020; Published: 29 September 2020

\begin{abstract}
Background: The primary goal of this study was to assess the effect of sand walking on Hemoglobin A1c (HbA1c), Body Mass Index (BMI), waist circumference, and quality of life among individuals with Type-2 Diabetes Mellitus (T2DM). (2) Methods: A randomized-controlled design was conducted on 66 overweight participants suffering from T2DM. Participants were randomly allocated to sand walking (SW) $(n=33)$ and normal walking (NW) $(n=33)$ groups. Participants performed moderate-intensity walking for $30 \mathrm{~min}, 3$ times a week for 4 months. Participants walking on sand had statistically significant mean scores for HbA1c, BMI, waist circumference and quality of life $((\mathrm{M}=7.32, \mathrm{SD}=0.47),(\mathrm{M}=25.77, \mathrm{SD}=1.366),(\mathrm{M}=92.94, \mathrm{SD}=2.59),(\mathrm{M}=91.48, \mathrm{SD}=34.08))$ than those walking on leveled surface $((\mathrm{M}=8.38, \mathrm{SD}=0.77), \mathrm{t}(52.8)=-6.73, p=0.003,(\mathrm{M}=26.80$, $\mathrm{SD}=1.38), \mathrm{t}(64)=-3.05, p=0.001,(\mathrm{M}=98.12, \mathrm{SD}=2.16 .3), \mathrm{t}(64)=-3.75, p=0.001,(\mathrm{M}=112$, $\mathrm{SD}=33.7), \mathrm{t}(64)=-2.45, p=0.017)$ respectively. (3) Conclusions: Regular SW with a healthy dietary regime for 4 months led to a statistically significant difference in $\mathrm{HbA1c}$, BMI, waist circumference, and quality of life as compared to NW group.
\end{abstract}

Keywords: diabetes mellitus; walking; rehabilitation

\section{Introduction}

Type 2 diabetesmellitus (T2DM) is one of the prevalent metabolic disorders worldwide [1]. Its prevalence has increased worldwide in the last three decades due to immobility, unhealthy dietary habits, environmental factors, and individual genetic vulnerability [2]. Diabetes mellitus is a global epidemic estimated to have affected 415 million people in 2015 and is estimated to reach 642 million by 2040 [3]. Developing countries like the Kingdom of Saudi Arabia (KSA), Bahrain, Kuwait, Qatar, Lebanon, and the United Arab Emirates are among the world's top countries with the highest prevalence of T2DM affecting 32.8 million people in 2011, expected to reach 60 million by 2030. In KSA, dietary habits [4], genetic predisposition, and sedentary lifestyle are the main cause of early-onset T2DMx [5].

Uncontrolled T2DM reported to cause multiple complications and alter the normal physiological process of the body. Prompt dietary management [6] and regular exercise are reported to improve blood glucose homeostasis and eventually improve the quality of life [7]. Physical activity such as regular walking is associated with multiple physical and psychological benefits [8]. Walking and a 
healthy diet is a cornerstone in the treatment of T2DM. Several studies have shown positive short-term effects of walking in T2DM $[9,10]$. Combination of walking and weight training is reported to cause cardiovascular adaptations, muscle hypertrophy, increased capillary density in the muscles of patients with T2DM as well as in healthy people [11]. Furthermore, 30 min of brisk walking is reported to improve blood glycemic metabolism and reduces cardiovascular risk factors, such as high blood pressure, lipid disorders, and fat mass buildup [12]. However, adults with, mild to moderate arthritic changes especially in knee joints make walking a bit more challenging. Sand walking would be a better alternative than firm surface walking, which is reported to produce less joint reaction forces. To the best of our knowledge, scientific literature lacks evidence about the effect of sand walking combined with individualized dietary intervention inT2DM. Therefore, the purpose of this study was to compare the effect of sand walking (SW) as compared to normal walking (NW) on glycemic metabolism, weight, and quality of life in T2DM. We hypothesize that there will be significant difference in better health benefits between participants in SW and NW group.

\section{Materials and Methods}

\subsection{Design}

We conducted a 16-week, multi-center, randomized controlled trial. Eligible participants were randomly assigned to sand-walking and normal walking group. The participants and therapists could not be blinded due to the apparent difference in the intervention in the two groups, but the therapists responsible for assessing outcome variables were blinded to the allocation of participants. The study protocol was reviewed and approved by the Deanship of Scientific Research at Majmmah University (MUREC- Oct. I 6/COM-201 8/5). Participants gave written informed consent before being enrollment in the study. The study began in January 2017 and was completed in September 2019.

\subsection{Setting}

We recruited participants by searching the records databases of the hospital and community health centers and by direct advertising. We also recruited participants from the outpatient physical therapy department of University affiliated Hospital (Figure 1). The Clinical trial was registered with the US clinical Trial Registry No. NCT04364685.

\subsection{Eligibility}

The inclusion criteria wereT2DM for more than one year, $\mathrm{HbA} 1 \mathrm{c}$ ranging from $7 \%$ to $10 \%$, $\mathrm{BMI}$ between $25-30 \mathrm{~kg} / \mathrm{m}^{2}$, age in the range of 40 to 75 years, and stable anti-diabetic treatment for the last 6 months and sedentary level of activity (activities restricted to activities of daily living). Participants with a history of recent myocardial infarction, diabetic neuropathy, using walking aids, and unstable angina, severe musculoskeletal disorders that make walking difficult, current cigarette or other forms of smoking, and severe respiratory disease were excluded. A comprehensive physical exam and counseling session were performed before the start of the group exercise session. Each participant was explained about the diet regime Appendix A recommended by a dietician. The participants reported their rate of perceived exertion on the 20-points Borg scale at the end of each 30-min walking session.

Acclimatization to exercises: Every eligible participant participated in a preparatory exercise 2 to 3 weeks before the commencement of the study. The exercises included walking on a firm surface for 10-20 min 3 times a week. Participants who were not regular $(n=1)$ or showed an abnormal cardiovascular response to exercise $(n=1)$ were excluded. 


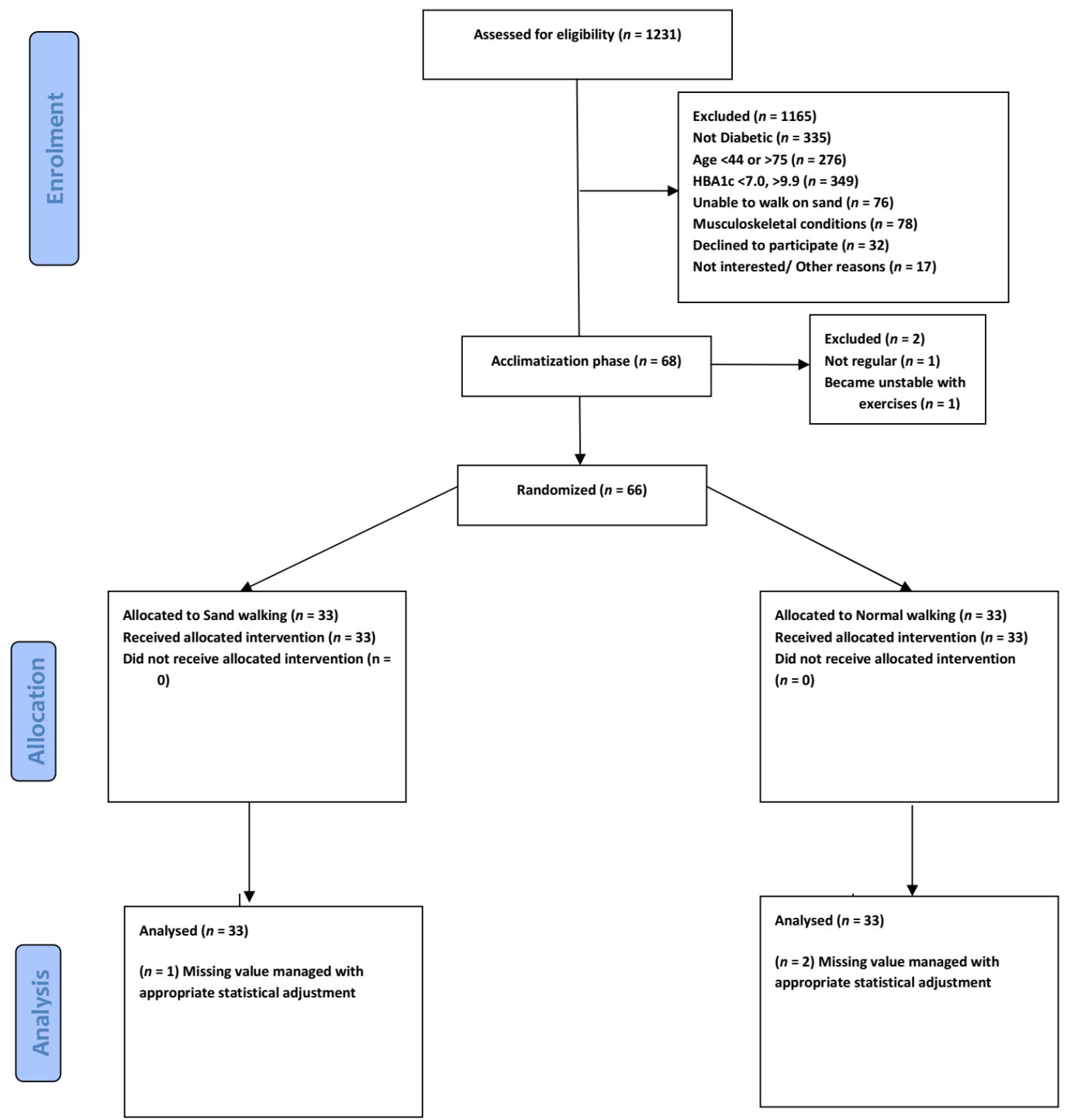

Figure 1. Consolidated Standards of Reporting Trials of participants through enrolment, allocation, and Analysis.

\subsection{Randomization}

Computer-generated random numbers were assigned to each of the eligible participants. These random numbers were printed on a paper separately and folded in a jar. A second person, who was not part of the study and neither was aware of the study protocol, picked these folded papers from the jar one by one and sorted them into two groups. The third person who was also not part of the study named the two groups of papers as control and experimental.

Procedure: The study consists of two groups NW $(n=33)$, SW $(n=33)$. Each intervention lasted for $45 \mathrm{~min}$, which consisted of $10 \mathrm{~min}$ of warm-up, $30 \mathrm{~min}$ walking intervention, and $5 \mathrm{~min}$ cool down. All the groups had to perform moderate-intensity walking, 3 times a week for 16weeks (4 months). Three physiotherapists supervised the treatment session. All sessions were scheduled in the morning. The physiotherapists involved were randomly assigned to supervise any of the two groups. To reduce attention bias all the participants were attended with equal enthusiasm. To effectively manage the risk of the hypoglycemic episode during or after the walking session, appropriate precautions were taken.

Participants in the NW group $(n=33)$ performed outdoor walking. A group walking session of moderate-intensity training for $30 \mathrm{~min}$ was conducted at the University Track and Field ground wearing 
their regular comfortable sports shoe. Vo2 max was not calculated during the training session, but the moderate intensity of exercise was reported on Borg rating for perceived exertion scale (level 13-14) [13]. Each participant was evaluated and interviewed by the fourth blinded physiotherapist not involved in the intervention, at the recruitment, and at the end of the 16th week.

Participants in the SW group performed walking on soft sand. Twenty-meter-long leveled soft sand was available within the vicinity of the university campus. The pathway of sand was primarily for annual university athletic meet. The sand was examined by three therapists for any sharp stones and was leveled after every session. The consistency of sand was such that the average weighted individual feet would easily be covered with sand up to the ankle joint. The patients wore their normal shoes with comfortable clothing. After every $10 \mathrm{~min}$ of walking, the therapist communicated with the participants to enquire about their state of exertion. Participants could take rests but were required to complete $30 \mathrm{~min}$ of walking using a stopwatch. All the participants took two to three rest periods before completing a full 30 min walking session.

Outcome measures: $\mathrm{HbA1c}, \mathrm{BMI}$, waist circumference, and quality of life were calculated at baseline and on the 16th week.

A laboratory assistant obtained a blood sample from the participants. HbA1c was analyzed using high-performance liquid chromatography. The normal range of $\mathrm{HbA1c}$ ranges from $4.5 \%$ to $6.3 \%$. The lipid profile was also measured by a standard method.

Bodyweight and height were measured by a standard weighting machine (Electronic BMI measuring height-weight scale machine-SGC200120, (Yiwe Sangong Fitness equipment Factory, Zhejiang, China). A standard inch tape was used to measure the waist circumference at the level of the posterior superior iliac spine.

Achieving dietary change requires strong will power and giving up long traditional patterns of eating practice. A dietician interviewed each participant to formulate a diet chart tailored to their body type and level of activity. The intention was not to reduce the weight but to make sure that the dietary intake was similar across the groups. Participants in the experimental and control groups showed a significant amount of compliance with the training and diet regime. Besides, the participants were instructed to remain active in their daily activities after the session.

Health-related quality of life was evaluated by the Arabic version of Diabetes 39 (D-39). D-39 includes thirty-nine questions with a total score of 253. Each question is rated on a Likert scale ranging with a score of 1 to 7 . Therefore, the minimum score is 39 , indicating the worst quality of life and the highest score is 253, indicating the highest level of quality of life. The Arabic version of the D-39 has been validated.

Dietary advice includes carbohydrates in the form of starch, avoiding refined sugar and usage of non-nutritive sweeteners, replacing food containing saturated fatty acids, salts consumption reduced to a minimum, diet with high quality of protein, small multiple meals over a day to avoid post-prandial peak blood sugar level. Other important instructions related to the type of food are provided in detail in the Appendix A.

\section{Results}

\subsection{Statistical Analysis}

The power analysis was performed by retrieving the data from a similar study [14]. To get statistical power of at least $95 \%$ (2-tailed $\alpha=0.05$ ), the minimum number of participants in each group must be 30. The total number of participants in this study was 69. Estimating a possible drop rate of $10 \%, 66$ participants were recruited for this study.

We conducted all analyses using the intent-to-treat principle. We conducted a descriptive analysis to obtain the missing value, revealed $3 \%(n=2), 1.5 \%(n=1)$, and $1.5 \%(n=1)$ of missing value from pre-test evaluation of BMI, pre-test evaluation of $\mathrm{HbA1c}$, and post-test of BMI, respectively. Little's Missing Completely at Random (MCAR)test was performed on the data set to analyse the missing 
values that are randomly missing (Little's MCAR test Chi square $=28.663, \mathrm{DF}=24, \mathrm{Sig}=0.233$ ). The results reported that the values missing are missing at random. Expectation maximization was used to replace the missing values separately for each variable, later the files were merged as one for analysis.

Our randomized controlled trial consists of 66 participants randomly allocated into experimental (sand walking, $N=33$ ) and control group (Normal walking, $N=33$ ). By comparison, the sand walking group is associated with better improvement in BMI, HbA1c, waist circumference, and quality of Life. To test the hypothesis that the sand walking was associated with statistically significantly different mean dependent variables, a student $t$-test was performed to test between-group (pre-test control with pre-test experimental) and paired sample $t$-test to analyses within-group mean difference (pre-test control with post-test control). To meet the assumption of the test, normality and homogeneity test was performed. All the variables met the assumption of normality; however, Post-test results of $\mathrm{HbA1c}$ failed the homogeneity of variance via Levine's F test, F (11.170), $p=0.001$. Therefore, the test output for the Post-HbA1c variable was interpreted as sphericity not assumed. $(\mathrm{F}=45.176, \mathrm{df}=52.872$, $p=0.001)$. All the other variables satisfied the assumptions and the post-test score was statistically significant in the experimental group. A graphical representation of means and the standard error of the mean is displayed in Figures 2 and 3.

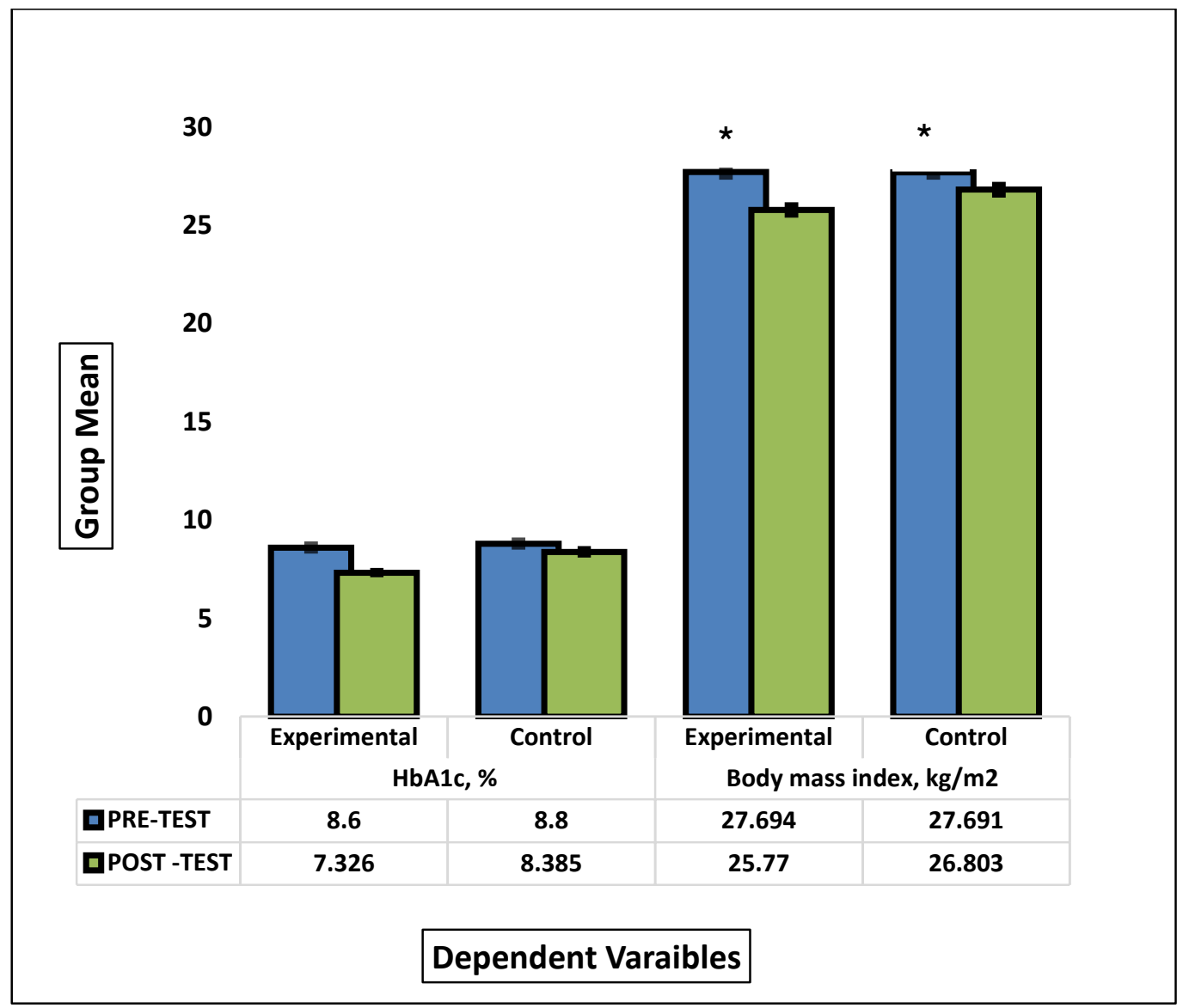

Figure 2. Comparison between the group means of $\mathrm{HbA} 1 \mathrm{c}$ and BMI before and after the intervention. * signify statistical significant different between pre-test and post test mean scores of experimental and control groups. 


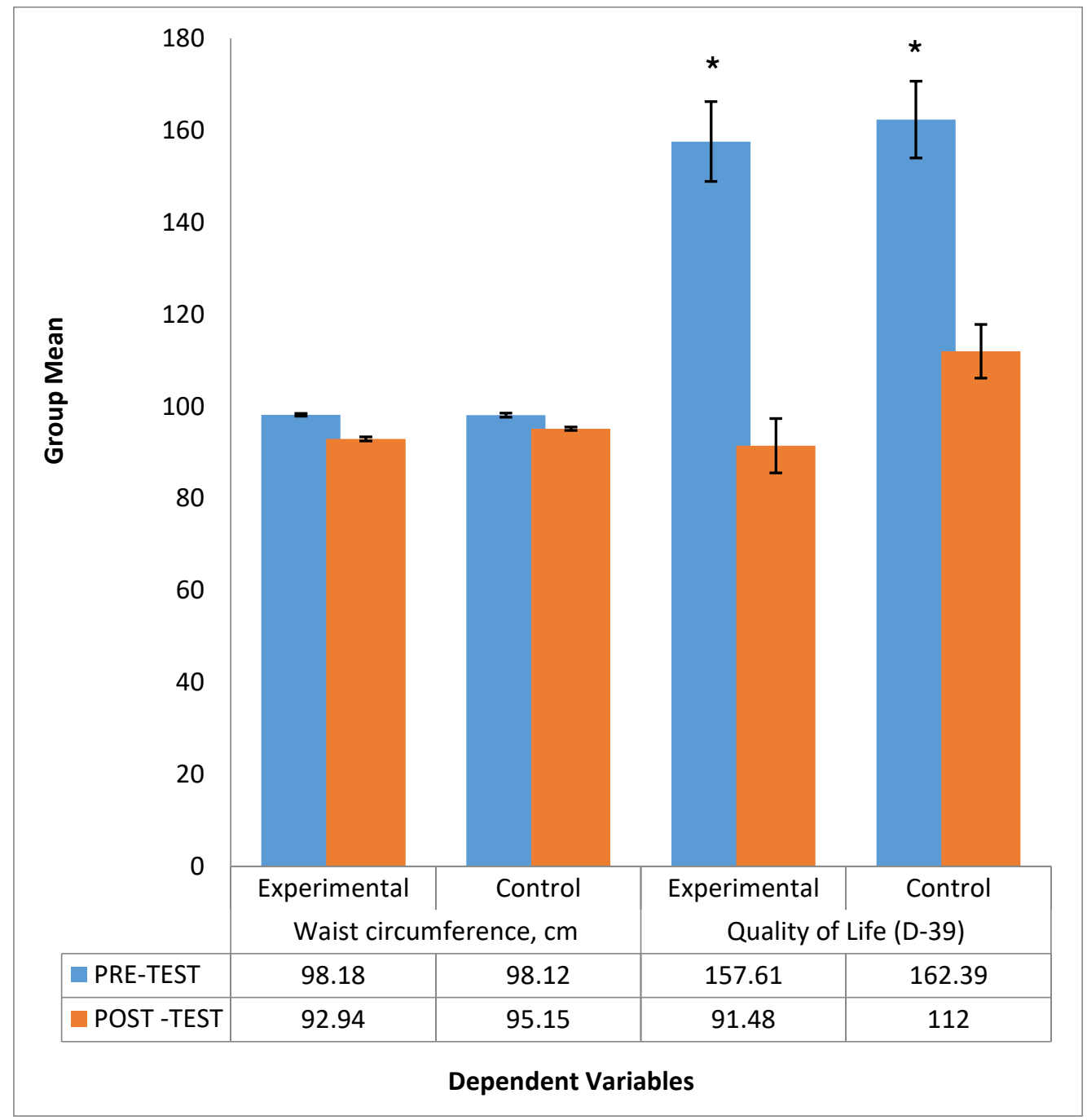

Figure 3. Comparison between the group mean of Waist circumference and Quality of life before andafter intervention. * signify statistical significant different between pre-test and post test mean scores of experimental and control groups.

We randomly selected 66 participants suffering from chronic T2DM, sedentary, and overweight. The participants were allocated randomly into two groups, Firm-surface walking $(n=33)$, Sand Walking $(n=33)$.

\subsection{Chi-Square Test (Categorical Data Analysis)}

A chi-square test of independence showed that there was no significant difference between gender distribution in the total sample, $\mathrm{X}^{2}(1, N=66)=1.515, p=0.218$. However, when analyzed with independent sample, $t$-test male participants $(M=93.50, S D=2.72)$ had significant reduction in waist circumference compared to female $(\mathrm{M}=94.79, \mathrm{SD}=2.31), t(64)=-2.015, p=0.048$. The baseline analysis of variables in the NW and SW groups such as age, gender, HbA1c, BMI, waist circumference, and quality of life were not statistically significant (Table 1). 
Table 1. Baseline and post-intervention mean difference between variables.

\begin{tabular}{|c|c|c|c|c|c|}
\hline Characteristics & Group & $\begin{array}{c}\text { NW } \\
(\mathrm{m} \pm \mathrm{SD}) \\
\text { Baseline }\end{array}$ & $\begin{array}{l}\text { Between Group } \\
\text { Difference }\left(p^{*}\right)\end{array}$ & $\begin{array}{c}\text { SW } \\
(\mathrm{m} \pm \mathrm{SD}) \\
\text { Post-Intervention }\end{array}$ & $\begin{array}{l}\text { Between Group } \\
\text { Difference }\left(p^{*}\right)\end{array}$ \\
\hline & & Pre-Intervention & Post-Intervention & & \\
\hline Males/Females & Experimental & $20 / 13$ & & - & - \\
\hline $\begin{array}{c}\text { Mean age (SD) } \\
y\end{array}$ & $\begin{array}{l}\text { Experimental } \\
\text { Control }\end{array}$ & $\begin{array}{l}52.8(8.924) \\
52.1(7.715)\end{array}$ & 0.713 & - & - \\
\hline $\mathrm{HbA} 1 \mathrm{c}, \%$ & $\begin{array}{l}\text { Experimental } \\
\text { Control }\end{array}$ & $\begin{array}{l}8.6 \pm 0.8746 \\
8.8 \pm 0.8682\end{array}$ & 0.355 & $\begin{array}{l}7.3 \pm 0.4706 \\
8.3 \pm 0.7726\end{array}$ & 0.003 \\
\hline $\begin{array}{c}\text { Body mass } \\
\text { index, } \mathrm{kg} / \mathrm{m}^{2}\end{array}$ & $\begin{array}{c}\text { Experimental } \\
\text { Control }\end{array}$ & $\begin{array}{l}27.6 \pm 1.2762 \\
27.6 \pm 1.2511\end{array}$ & 0.992 & $\begin{array}{l}25.7 \pm 1.3664 \\
26.8 \pm 1.3828\end{array}$ & 0.001 \\
\hline $\begin{array}{c}\text { Waist } \\
\text { circumference, }\end{array}$ & $\begin{array}{l}\text { Experimental } \\
\text { Control }\end{array}$ & $\begin{array}{l}98.2 \pm 1.793 \\
98.1 \pm 1.996\end{array}$ & 0.897 & $\begin{array}{l}92.9 \pm 2.597 \\
95.1 \pm 2.167\end{array}$ & 0.001 \\
\hline $\begin{array}{l}\text { Quality of Life } \\
\text { (D-39) }\end{array}$ & $\begin{array}{c}\text { Experimental } \\
\text { Control }\end{array}$ & $\begin{array}{l}157.6 \pm 49.801 \\
162.3 \pm 48.069\end{array}$ & 0.692 & $\begin{array}{c}91.4 \pm 34.089 \\
112.0 \pm 33.706\end{array}$ & 0.017 \\
\hline
\end{tabular}

NW, Normal walking; SW, Sand walking; m, mean; SD, Standard Deviation; $p^{*}$, independent sample $t$-test.

\subsection{Within-Group and between-Group Analysis}

The independent sample $t$-test demonstrated a statistically significant mean difference between the experimental group (Sand walking) as compared to control group (Normal walking) for HbA1c $(t(52.8)=-6.73, p=0.003), \mathrm{BMI}(t(64)=-3.05, p=0.001)$, waist circumference $(t(64)=-3.75, p=0.001)$, and quality of life $(t(64)=-2.45, p=0.017)$ (Table 1$)$. The within-group pre-test and post-test analyses of each variable were performed by paired sample $t$-test for $\mathrm{HbA1c}$, BMI, waist circumference, and quality of life. There is a statistically significant difference in the mean scores of dependent variables before and after the intervention in both the groups (Table 2).

Table 2. Pre-posttest analysis within the group by Paired sample $t$-test for within-group difference.

\begin{tabular}{|c|c|c|c|c|c|c|c|c|}
\hline \multirow{3}{*}{ Variables } & \multicolumn{8}{|c|}{ Paired Differences (Control) } \\
\hline & \multirow{2}{*}{ Mean } & \multirow{2}{*}{ Std. Deviation } & \multirow{2}{*}{ Std. Error Mean } & \multicolumn{2}{|c|}{ 95\% Confidence Interval } & \multirow{2}{*}{$t$} & \multirow{2}{*}{ df } & \multirow{2}{*}{$p$} \\
\hline & & & & Lower & Upper & & & \\
\hline BMI & 0.8 & 0.8838 & 0.1538 & 0.5745 & 1.2013 & 5.771 & 32 & 0.001 \\
\hline $\mathrm{HbA} 1 \mathrm{c}$ & 0.5 & 0.9817 & 0.1709 & 0.0670 & 0.7633 & 2.429 & 32 & 0.021 \\
\hline Waist Circumference (cm) & 3 & 2.215 & 0.386 & 2.184 & 3.755 & 7.703 & 32 & 0.001 \\
\hline \multirow[t]{2}{*}{ Variables } & \multirow{2}{*}{ Mean } & \multirow{2}{*}{ Std. Deviation } & \multirow{2}{*}{ Std. Error Mean } & \multicolumn{2}{|c|}{$95 \%$ Confidence Interval } & \multirow{2}{*}{$t$} & \multirow{2}{*}{ df } & \multirow{2}{*}{$p$} \\
\hline & & & & Lower & Upper & & & \\
\hline BMI & 0.9 & 0.5013 & 0.0873 & 1.7465 & 2.1020 & 22.052 & 32 & 0.001 \\
\hline $\mathrm{HbA} 1 \mathrm{c}$ & 1.3 & 0.9713 & 0.1691 & 0.9292 & 1.6181 & 7.532 & 32 & 0.001 \\
\hline
\end{tabular}

BMI, Body Mass Index; HbA1c, Hemoglobin A1c; $t, t$-value of the test; df, degree of freedom; $p$, Significance; QOL, Quality of life; m, mean; SD, Standard Deviation; $p$, Paired sample $t$-test.

\section{Discussion}

Our study aimed to evaluate the effect of sand walking on $\mathrm{HbA1c}$ and other health indicators in people with T2DM. There was significant mean change in $\mathrm{HbA1c}(1.3 \%)$, BMI $\left(0.9 \mathrm{~kg} / \mathrm{m}^{2}\right)$, waist circumference (5.3), and Quality of life (66.2) in SW group as compared to HbA1c $(0.5 \%)$, BMI $\left(0.8 \mathrm{~kg} / \mathrm{m}^{2}\right)$, waist circumference (3cm), and Quality of life (50.3) in NW group. 
The change in $\mathrm{HbA1c}$ in NW group $(0.5 \%)$ was similar to a recent study reported that the combination of recommended diet and exercises will result in a better reduction $(0.041 \%)$ in the elevated $\mathrm{HbA1c}$ [15]. However, the significant reduction of 1.3\% in $\mathrm{HbA1c}$ in SW group could be due to effect of walking on sand and the typically characteristics of our sample, that is, sedentary, overweight, and chronic T2DM. We used soft sand as a pathway for our experimental group participants to perform walking. Sand could provide an ideal surface, if the patient suffers from increased pain due to increased joint reaction forces or arthritis [16]. Researchers have reported reduced joint reaction forces and increased energy expenditure during sand walking [17]. There is little research available that uses sand as an interface to treat various neuromuscular disabilities or general systemic disorder. One of the studies on stroke [18] and multiple sclerosis [19] uses sand as a pathway to train walking. Both researches have reported improvement in gait parameters. In our study, participants performed 90 min of walking per week, (30 min of walking 3 times a week). A recent review and meta-analysis [20] reported the use of structured exercises must be more than $150 \mathrm{~min}$ per week to be associated with health benefits. A duration of exercises of more than 150 min reduced $\mathrm{HbA} 1 \mathrm{c}$ by $0.89 \%$ as compared to $0.36 \%$ when the duration was less than $150 \mathrm{~min}$. Some studies employed a higher intensity of training [21] and included participants with higher BMI and found a significant reduction in $\mathrm{HbA1c}$ [22]. It was reported that lifestyle interventions are more efficient among individuals with a BMI higher than $25 \mathrm{~kg} / \mathrm{m}^{2}$. Higher intensity of exercises among participants with T2DM requires a high level of dedication and effort from the individual.

In the control group, there was a mean change of $0.8 \mathrm{~kg} / \mathrm{m}^{2}$ in BMI as compared to $0.9 \mathrm{~kg} / \mathrm{m}^{2}$ in the experimental group. Similar findings were also reported in a study that used low-calorie diet with exercise and found a reduction in waist circumference, BMI, and better glycemic homeostasis among individuals suffering from T2DM [23]. In our study, we used a more pragmatic approach towards dietary control, as the level of activity of our participants was sedentary, overweight, and middle-aged [24,25].

Our study reported a reduction in waist circumference among participants in the SW group of around $5.3 \mathrm{~cm}$ as compared to $3 \mathrm{~cm}$ in participants in NW walking. A recent study has reported that there is a positive relationship between the waist circumference and mortality. Waist circumference is also a valid tool to predict cardiovascular diseases in the future.

Quality of life assessed by D-39 showed moderate improvement in both groups. However, scores were better in SW group as compared to NW group. A similar study reported improvement in mental health and SF-36 score with 9-month resistance training as compared to aerobic and combined training [26]. A recent cross-sectional study also demonstrated the cognitive effect of T2DM. The study concluded that there is a significant association between depression, anxiety, and T2DM [27].A study examines the relationship between the health-related quality of life and physical activity in T2DM. They found a negative correlation between the quality of life and the level of physical activity. A study by Duviviers et al. [28] reported that $60 \mathrm{~min}$ of moderate-intensity exercises are sufficient to overcome the negative effects sitting for the rest of the day. It was also reported that short bouts of sitting showed a beneficial effect on insulin sensitivity and the level of blood plasma [29]. Six-minutes' walk test has been reported to have a significant correlation with $\mathrm{HbAc1}$ (Relative Precision 1.57, $\chi^{2}<0.05$ ). The 6-min walk test is reported to be strong to predict the physical capacity of the individual with T2DM [30].

A prospective cohort study involving 4681 healthy adults conducted between 1981-2016 found that higher muscle strength is associated with a lower risk of development of T2DM [31]. A study reported improvement in glucose and lipid metabolism after light bouts of exercises after prolonged sitting in an individual with T2DM [32]. The sedentary busy lifestyle makes it difficult to adhere to the structured exercise protocol. The main goal of our study was to determine realistic training (superior walking method) combined with dietary restriction. Moreover, sand walking was an enjoyable experience for all the participants and required more effort than normal firm surface walking. The scientific literature has reported that sand walking increases the cost of energy [33], reduces walking velocity [34], improves lower limb strength [35], and increases relative muscular activity to maintain balance [36] as 
compared to the flat surface. These factors might directly or indirectly influence the change in the level of $\mathrm{HbA1c}, \mathrm{BMI}$, waist circumference, and quality of life.

There are limitations in our study. The number of participants in the study was relatively small. Future studies must consider involving large samples to obtain robust evidence. The research included overweight diabetic participants without any associated disorders. Therefore, the results of the study cannot be generalized to the diabetic population with associated disorders. The participants reported self-perceived moderate intensity exertion levels through Borg rating for perceived exertion scale. The level perception of moderate-intensity of exercises might have been overestimated or underestimated by the participants. The speed and distance traveled by the participants were not calculated. Future studies may use gadgets to measure the temporal and spatial characteristics of gait.

\section{Conclusions}

There was a significant change in $\mathrm{HbA1c}$, BMI, Waist circumference and quality of life in the patient with T2DM after 4 months of sand walking training and dietary control.

Author Contributions: Conceptualization, M.S. and F.K.; methodology, F.A.; software, M.A. (Mehrunnisha Ahmad); validation, M.A. (Mazen Alqahtan), M.A. (Mehrunnisha Ahmad), and M.S.; formal analysis, M.A. (Mazen Alqahtan); investigation, F.K.; resources, M.A. (Msaad Alzhrani); data curation, M.A. (Msaad Alzhrani); writing-original draft preparation, F.K.; writing-review and editing, M.S.; visualization, F.K.; supervision, M.A. (Mazen Alqahtan); project administration, M.A. (Msaad Alzhrani); funding acquisition, M.S. All authors have read and agreed to the published version of the manuscript.

Funding: This research was funded by Deanship of Scientific Research, grant number R-1441-168, and the APC was funded by Deanship of Scientific Research.

Acknowledgments: We are highly indebted to the physiotherapy staff and laboratory assistant at King Khalid hospital for supervising the group session of walking training.

Conflicts of Interest: The authors declare no conflict of interest. The funders had no role in the design of the study; in the collection, analyses, or interpretation of data; in the writing of the manuscript; or in the decision to publish the results.

\section{Appendix A}

1. Dietary advice to all the participants.

2. Modern dietary management of diabetes essentially involves modifications of the quality and quantity of food to be taken by the diabetic patient. The following guidelines apply to diabetes irrespective of type, weight status, age, gender, or occupation.

3. Most of the carbohydrate consumed should be in the form of starch (polysaccharides) such as maize, rice, beans, bread, potatoes, etc.

4. Dates are the staple food in Middle East. Although the dates contain high fiber content the glycemic index is also high. Therefore, all participants were instructed to limit the intake of dates from 3-5/day. All refined sugars such as glucose, sucrose, and their products (soft drinks, sweets, toffees, etc.) and honey should be avoided, except during severe illness or episodes of hypoglycemia. These foods contain simple sugar, which is easily absorbed causing a rapid rise in blood sugar.

5. Instead of sugar, non-nutritive sweeteners, e.g., Canderel, saccharine, NutraSweet, aspartames are suitable.

6. Animal fat such as butter, lard, egg yolk, and other foods high in saturated fatty acids and cholesterol should be reduced to a minimum and be replaced with vegetable oils, particularly polyunsaturated fats.

7. Salt should be reduced whether hypertensive or not.

8. Protein (fish, meat, beans, crab, crayfish, soybean, chicken, etc.) and salt are restricted for those with diabetic nephropathy. 
9. Cigarette smoking should be avoided by diabetic patients. Alcohol should be taken only in moderation.

10. The items allowed for free consumption include Water, green leafy vegetables, tomatoes, onions, cucumber, aubergine, peppers, vegetable salad without cream. Any brand of tea, coffee, or drinks that contain very low or no calories.

11. For patients too ill to eat solid food, fluid or semi-solid diet should be substituted (papaya, soya bean, custard, etc.).

12. Patients treated with insulin or certain oral hypoglycemic agents, e.g., sulfonylureas must be advised to eat regularly and often to prevent hypoglycemia- 3 meals a day plus suitable snacks in between, e.g., fresh fruits.

13. Small meals spaced over the day, rather than 1 or 2 big meals, help avoid post-pyramidal peaks in blood sugar.

\section{References}

1. Younossi, Z.; Anstee, Q.M.; Marietti, M.; Hardy, T.; Henry, L.; Eslam, M.; George, J.; Bugianesi, E. Global burden of NAFLD and NASH: Trends, predictions, risk factors and prevention. Nat. Rev. Gastroenterol. Hepatol. 2017, 15, 11-20. [CrossRef] [PubMed]

2. Zheng, Y.; Ley, S.H.; Hu, F.B. Global aetiology and epidemiology of type 2 diabetes mellitus and its complications. Nat. Rev. Endocrinol. 2017, 14, 88-98. [CrossRef] [PubMed]

3. Ogurtsova, K.; Fernandes, J.D.R.; Huang, Y.; Linnenkamp, U.; Guariguata, L.; Cho, N.; Cavan, D.; Shaw, J.; Makaroff, L.E. IDF Diabetes Atlas: Global estimates for the prevalence of diabetes for 2015 and 2040. Diabetes Res. Clin. Pract. 2017, 128, 40-50. [CrossRef] [PubMed]

4. Naji, E.; Kashoo, F.Z.; Kashoo, M. Prevalence of Obesity and Overweight among Majmaah University Students. Indian J. Physiother. Occup. Ther. Int. J. 2013, 7, 40. [CrossRef]

5. Malik, A.R. Diabetes mellitus in the Arab world. J. Taibah Univ. Med. Sci. 2016, 11, 283. [CrossRef]

6. Sami, W.; Ansari, T.; Butt, N.S.; AbHamid, M.R. Effect of diet on type 2 diabetes mellitus: A review. Int. J. Health Sci. 2017, 11, 65-71.

7. Khan, A.; Mundra, P.A.; Straznicky, N.E.; Nestel, P.J.; Wong, G.; Tan, R.; Huynh, K.; Ng, T.W.; Mellett, N.A.; Weir, J.M.; et al. Weight Loss and Exercise Alter the High-Density Lipoprotein Lipidome and Improve High-Density Lipoprotein Functionality in Metabolic Syndrome. Arter. Thromb. Vasc. Boil. 2018, 38, 438-447. [CrossRef]

8. Ahmad, I.; Shaphe, A. Effect of Aerobic Exercises on Blood Pressure in Mild and Moderate Hypertensive Middle Aged and Older Patients. Majmaah J. Health Sci. 2013, 1, 46-52. [CrossRef]

9. Dempsey, P.C.; Larsen, R.N.; Sethi, P.; Sacre, J.W.; Straznicky, N.E.; Cohen, N.; Cerin, E.; Lambert, G.W.; Owen, N.; Kingwell, B.A.; et al. Benefits for Type2 Diabetes of Interrupting Prolonged Sitting with Brief Bouts of Light Walking or Simple Resistance Activities. Diabetes Care 2016, 39, 964-972. [CrossRef]

10. Alqahtani, M.M.; Kashoo, F.Z.; Ahmad, F. Current scenario of evidence-Based practice and rationale of preferred approach in stroke rehabilitation among physiotherapists in Saudi Arabia: Across-Sectional survey. Saudi J. Health Sci. 2019, 53-64. [CrossRef]

11. Zanuso, S.; Sacchetti, M.; Sundberg, C.J.; Orlando, G.; Benvenuti, P.; Balducci, S. Exercise in type 2 diabetes: Genetic, metabolic and neuromuscular adaptations. A review of the evidence. Br. J. Sports Med. 2017, 51, 1533-1538. [CrossRef] [PubMed]

12. Kokic, I.S.; Ivanisevic, M.; Biolo, G.; Simunic, B.; Kokic, T.; Pisot, R. P-68 the impact of structured aerobic and resistance exercise on the course and outcomes of gestational diabetes mellitus: A randomised controlled trial. Br. J. Sports Med. 2016, 50. [CrossRef]

13. Cleland, B.T.; Ingraham, B.A.; Pitluck, M.C.; Woo, D.; Ng, A.V. Reliability and Validity of Ratings of Perceived Exertion in Persons with Multiple Sclerosis. Arch. Phys. Med. Rehabil. 2016, 97, 974-982. [CrossRef] [PubMed]

14. Gainey, A.; Himathongkam, T.; Tanaka, H.; Suksom, D. Effects of Buddhist walking meditation on glycemic control and vascular function in patients with type2 diabetes. Complement. Ther. Med. 2016, 26, 92-97. [CrossRef] [PubMed] 
15. McKenzie, A.L.; Hallberg, S.J.; Creighton, B.C.; Volk, B.M.; Link, T.M.; Abner, M.K.; Glon, R.; McCarter, J.P.; Volek, J.S.; Phinney, S.D.; et al. A Novel Intervention Including Individualized Nutritional Recommendations Reduces Hemoglobin A1c Level, Medication Use, and Weightin Type2 Diabetes. JMIR Diabetes 2017, 2, e5. [CrossRef]

16. Crevier-Denoix, N.; Robin, D.; Pourcelot, P.; Falala, S.; Holden, L.; Estoup, P.; Desquilbet, L.; Denoix, J.M.; Chateau, H. Ground reaction force and kinematic analysis of limb loading on two different beach sand tracks in harness trotters. Equine Veter. J. 2010, 42, 544-551. [CrossRef]

17. Jafarnezhadgero, A.; Fatollahi, A.; Amirzadeh, N.; Siahkouhian, M.; Granacher, U. Ground reaction forces and muscle activity while walking on sand versus stable ground in individuals with pronated feet compared with healthy controls. PLoS ONE 2019, 14, e0223219. [CrossRef]

18. Kim, T.-H.; Hwang, B.-H. Effects of gait training on sand on improving the walking ability of patients with chronic stroke: A randomized controlled trial. J. Phys. Ther. Sci. 2017, 29, 2172-2175. [CrossRef]

19. Van den Berg, M.E.L.; Barr, C.; McLoughlin, J.V.; Crotty, M. Effect of walking on sand on gait kinematics in individuals with multiple sclerosis. Mult. Scler. Relat. Disord. 2017, 16, 15-21. [CrossRef]

20. Ostman, C.; Jewiss, D.; King, N.; Smart, N.A. Clinical outcomes to exercise training in type1 diabetes: A systematic review and meta-analysis. Diabetes Res. Clin. Pract. 2017, 139, 380-391. [CrossRef]

21. Caron, N.; Peyrot, N.; Caderby, T.; Verkindt, C.; Dalleau, G. Effect of type2 diabetes on energy cost and preferred speed of walking. Graefe's Arch. Clin. Exp. Ophthalmol. 2018, 118, 2331-2338. [CrossRef]

22. Støa, E.M.; Meling, S.; Nyhus, L.-K.; Mangerud, K.M.; Helgerud, J.; Bratland-Sanda, S.; Støren, Ø.; Strømstad, G. High-intensity aerobic interval training improves aerobic fitness and $\mathrm{HbA1c}$ among persons diagnosed with type2 diabetes. Graefe's Arch. Clin. Exp. Ophthalmol. 2017, 117, 455-467. [CrossRef]

23. Hamasaki, H. Daily physical activity and type2 diabetes: A review. World J. Diabetes 2016, 7, $243-251$. [CrossRef] [PubMed]

24. Sentinelli, F.; LaCava, V.; Serpe, R.; Boi, A.; Incani, M.; Manconi, E.; Solinas, A.; Cossu, E.; Lenzi, A.; Baroni, M. Positive effects of Nordic Walking on anthropometric and metabolic variables in women with type2 diabetes mellitus. Sci. Sports 2015, 30, 25-32. [CrossRef]

25. Cai, H.; Li, G.; Zhang, P.; Xu, D.; Chen, L. Effect of exercise on the quality of life in type 2 diabetes mellitus: A systematic review. Qual. Life Res. 2016, 26, 515-530. [CrossRef]

26. Hart, P.D.; Buck, D.J. The effect of resistance training on health-related quality of life in older adults: Systematic review and meta-analysis. Health Promot. Perspect. 2019, 9, 1-12. [CrossRef]

27. Al-Mohaimeed, A.A. Prevalence and factors associated with anxiety and depression among type 2 diabetes in Qassim: A descriptive cross-sectional study. J. Taibah Univ. Med. Sci. 2017, 12, 430-436. [CrossRef]

28. Duvivier, B.M.F.M.; Bolijn, J.E.; Koster, A.; Schalkwijk, C.G.; Savelberg, H.H.C.M.; Schaper, N.C. Reducing sitting time versus adding exercise: Differential effects on biomarkers of endothelial dysfunction and metabolic risk. Sci. Rep. 2018, 8, 8657. [CrossRef]

29. Thorp, A.A.; Kingwell, B.; Sethi, P.; Hammond, L.; Owen, N.; Dunstan, D. Alternating Bouts of Sitting and Standing Attenuate Postprandial Glucose Responses. Med. Sci. Sports Exerc. 2014, 46, 2053-2061. [CrossRef]

30. Meléndez, A.R.; Vázquez, P.A.; Lecona, I.L.; Garza, R.L. Correlación entre prueba de marcha de 6 minutos y prueba de esfuerzo máxima en pacientes con diabetes mellitus de tipo ii. Rehabilitación 2018, 53, 2-7. [CrossRef]

31. Wang, Y.; Lee, D.-C.; Brellenthin, A.G.; Sui, X.; Church, T.S.; Lavie, C.J.; Blair, S.N. Association of Muscular Strength and Incidence of Type2 Diabetes. Mayo Clin. Proc. 2019, 94, 643-651. [CrossRef] [PubMed]

32. Benatti, F.B.; Ried-Larsen, M. The Effects of Breaking up Prolonged Sitting Time. Med. Sci. Sports Exerc. 2015, 47, 2053-2061. [CrossRef] [PubMed]

33. Zamparo, P.; Perini, R.; Orizio, C.; Sacher, M.; Ferretti, G. The energy cost of walking or running on sand. Graefe's Arch. Clin. Exp. Ophthalmol. 1992, 65, 183-187. [CrossRef] [PubMed]

34. Davies, S.E.H.; MacKinnon, S.N. The energetics of walking on sand and grass at various speeds. Ergonomics 2006, 49, 651-660. [CrossRef] 
35. Morrison, K.; Braham, R.A.; Dawson, B.; Guelfi, K. Effect of a sand or firm-surface walking program on health, strength, and fitness in women 60-75 years old. J. Aging Phys. Act. 2009, 17, 196-209. [CrossRef]

36. Hwang, B.-H.; Kim, T.-H. The effects of sand surface training on changes in the muscle activity of the paretic side lower limb and the improvement of dynamic stability and gait endurance in stroke patients. J. Exerc. Rehabil. 2019, 15, 439-444. [CrossRef]

(C) 2020 by the authors. Licensee MDPI, Basel, Switzerland. This article is an open access article distributed under the terms and conditions of the Creative Commons Attribution (CC BY) license (http://creativecommons.org/licenses/by/4.0/). 